\title{
Negative Mood and Alcohol Problems are Related to Respiratory Dynamics in Young Adults
}

\author{
Paul Lehrer ${ }^{1, \dagger}$, Jennifer F. Buckman², Eun-Young Mun², Evgeny G. Vaschillo², Bronya \\ Vaschillo ${ }^{2}$, Tomoko Udo, , Tam Nguyen ${ }^{2}$, and Marsha E. Bates ${ }^{1,2}$ \\ ${ }^{1}$ Rutgers, The State University of New Jersey - Robert Wood Johnson Medical School \\ ${ }^{2}$ Center of Alcohol Studies, Rutgers, The State University of New Jersey
}

\section{Abstract}

This study examined the relationship of negative affect and alcohol use behaviors to baseline respiration and respiratory response to emotional challenge in young adults $(N=138,48 \%$ women). Thoracic-to-abdominal ratio, respiratory frequency and variability, and minute volume ventilation (MVV) were measured during a low-demand baseline task, and emotional challenge (viewing emotionally-valenced, emotionally-neutral, and alcohol-related pictures). Negative Mood and Alcohol Problems principal components were generated from self-report measures of negative affect and mood, alcohol use, and use-related problems. The Negative Mood component was positively related to a thoracic bias when measured throughout the study (including baseline and picture exposure). There was generally greater respiratory activity in response to the picture cues, although not specifically in response to the content (emotional or alcohol-related) of the picture cues. The Alcohol Problems component was positively associated with respiratory reactivity to picture cues, when baseline breathing patterns were controlled. Self-report arousal data indicated that higher levels of negative mood, but not alcohol problems, were associated with greater arousal ratings overall. However, those with alcohol problems reported greater arousal to alcohol cues, compared to emotionally neutral cues. These results are consistent with theories relating negative affect and mood to breathing patterns as well as the relationship between alcohol problems and negative emotions, suggesting that the use of respiratory interventions may hold promise for treating problems involving negative affect and mood, as well as drinking problems.

\section{Keywords}

Respiration; Thoracic Breathing; Anxiety; Depression; Alcohol Use

The respiratory system is exquisitely sensitive to variations in emotion and may be an important component of emotional regulation. Respiration provides oxygen to tissues, and subtle yet continual changes in respiration ensure that the body can effectively respond to variations in the metabolic needs of muscles, peripheral organs, and the brain. The respiratory system can also anticipate needed changes by responding to symbolic activity or conditional stimuli associated with increased or decreased demand in the past (Van den Bergh et al., 1999; Van Diest, Bradley, Guerra, Van den Bergh, \& Lang, 2009; Van Diest et al., 2006). Changes in respiration can thus be expected to occur in response to various cues

\footnotetext{
${ }^{\dagger}$ Correspondence may be sent to Paul Lehrer at Department of Psychiatry, Rutgers, Robert Wood Johnson Medical School, 671 Hoes Lane, Piscataway, NJ 08854, or via lehrer@umdnj.edu.

Current address: Department of Psychiatry, Yale University School of Medicine

Preliminary findings were presented at the annual meeting of the Association for Advancement of Respiratory Psychophysiology, Berlin, Germany, Oct. 26-28, 2009.
} 
associated with emotional arousal. Indeed, it is well established that respiratory activity decreases during periods of rest and relaxation (e.g., Reddy \& Nagendra, 2000) and increases in response to physical (Blaber, Hartley, \& Pretorius, 2003), chemical (Alvarez et al., 2007) and psychological (e.g., Ritz, Wilhelm, Meuret, Gerlach, \& Roth, 2009) challenges. Similarly, people with chronically high levels of anxiety (Freire \& Nardi, 2012; Garcia de Miguel, Nutt, Hood, \& Davies, 2012; Gold, 2011; Nardi, Freire, \& Zin, 2009; Ritz, Meuret, \& Ayala, 2010) or anger (Miller et al., 2013; Rivera-Arzola \& Ramos-Grenier, 1997) tend to show generalized elevations in respiratory activity, as well as increased levels of both general physiological arousal and heightened perception of somatic symptoms (e.g., Brown, Chorpita, \& Barlow, 1998; Hoehn-Saric \& McLeod, 2000).

Research has also shown that individuals with heightened anxiety demonstrate greater respiratory variability (Abelson, Weg, Nesse, \& Curtis, 2001). Variable breathing and periodic breath holding may contribute to hyperventilation, primarily through greater inhalation during sighing or yawning (Courtney \& Cohen, 2008). Additionally, thoracic breathing appears to be characteristic of stress and anxiety. Shifting from abdominal to thoracic breathing has been found to be associated with increased tidal volume and minute volume ventilation (MVV) (Gomez, Stahel, \& Danuser, 2004; Panka et al., 2010), and thus may be a mechanism for mobilizing the body to meet demands of physical effort.

To reduce negative affect, many individuals, especially those with high levels of anxiety, depression, and other negative emotional states, use drugs and alcohol (Cooper, Frone, Russell, \& Mudar, 1995; Cox \& Klinger, 1988; Grant, Stewart, \& Mohr, 2009; Koob \& Le Moal, 2001; Labouvie \& Bates, 2002; R. J. Pandina, Johnson, \& Labouvie, 1992). Persistent emotional distress and negative affect are risk factors for the development of substance use disorders (Koob, 2009; Koob \& Le Moal, 1997). The present study examined the relationships among respiratory functions, negative mood, and risky alcohol use. This was a component of a larger research program aimed at investigating regulatory flexibility in the autonomic nervous system that modulates emotional arousal and unhealthy drinking behaviors. Although the research design did not include all potentially relevant parameters of respiration, it did provide data from a sizeable sample of young adults who vary in negative affect and substance use involvement. To assess the dynamic functioning of the respiratory system associated with negative mood and alcohol use patterns, we examined whether these variables were related to respiration both at baseline and in response to emotional stimulation. We hypothesized that negative mood and intensity of alcohol use and problems would be associated with more rapid breathing, greater respiratory variability, and thoracic dominance in response to emotional stimulation, particularly in response to picture cues that, respectively, evoke negative affect or depict images associated with alcohol consumption. We also looked for differences among subjects in negative affect and mood and alcohol use with respect to differential patterns of respiration and self-report of emotional reaction to affect-arousing picture cues.

Finally, among practitioners using methods of applied psychophysiology to treat emotional disorders, paced or slow breathing, often in the context of heart rate variability biofeedback, yoga, or qi gong, is frequently used and has been found efficacious as a treatment component for problems involving negative affect, including anxiety (Clark \& Hirschman, 1990; Franzblau, Echevarria, Smith, \& Van Cantfort, 2008; Henriques, Keffer, Abrahamson, \& Horst, 2011; M. Paul \& Garg, 2012; Shenefelt, 2010; Thurber, 2007; Tweeddale, Rowbottom, \& McHardy, 1994; Wells, Outhred, Heathers, Quintana, \& Kemp, 2012) and depression (Beckham, Greene, \& Meltzer-Brody, 2013; Brown \& Gerbarg, 2005; Karavidas et al., 2007; Sato, Kawamura, \& Yamagiwa, 2011; Siepmann, Aykac, Unterdorfer, Petrowski, \& Mueck-Weymann, 2008; Tsang, Fung, Chan, Lee, \& Chan, 2006; Tweeddale et al., 1994). Preliminary studies have been done for treatment of substance abuse (Chen, 
Comerford, Shinnick, \& Ziedonis, 2010; Ospina et al., 2008). Credibility of this approach would be enhanced by establishing a relationship between these mood states and respiratory variables.

\section{METHODS}

This study was approved by the Institutional Review Boards for the Protection of Human Subjects Involved in Research of Rutgers University and of the University of Medicine and Dentistry of New Jersey. All participants were volunteers who provided written informed consent to take part in the study.

\section{Subjects}

Participants included 139 young adults, who took part in studies that examined heart rate variability (HRV) reactivity to emotional and alcohol-related stimuli. Results of HRV to visual stimuli have been published elsewhere (Bates et al., 2011; Buckman et al., 2010; Eddie et al., 2013). Forty-four participants were recruited from a college community by advertising for "social drinkers." Twenty-one participants were recruited as college student athletes. Forty-seven were recruited as college students who had previously been mandated to a brief alcohol intervention for violating university policies about on-campus substance use. Twenty-seven, similarly aged volunteers were recruited from consecutive voluntary admissions to a local, inpatient addiction treatment facility. One case was dropped from subsequent analysis because respiratory frequency data suggested that piezoelectric respiratory transducers slipped. Thus, the total sample for this present study was based on a sample of 138 young adults ( $48 \%$ women, $72 \%$ White, $\mathrm{M}=21.2, S . D .=2.2$ years of age).

The four groups differed in their negative affect and alcohol use patterns, providing a wide range of valid observations. We combined these groups in order to examine how respiratory dynamics are related to a wide continuum of negative mood and drinking behaviors, instead of treating them as distinctive groups. Although they were quite similar on a number of demographic characteristics (e.g., gender, socioeconomic status, and ethnicity), some of the groups statistically differed in terms of age and education. We did not control these variables or group membership in subsequent analyses because controlling for these variables would have reduced the observed range of the key variables (e.g., negative mood and drinking patterns).

Potential participants were excluded if they reported a history of a psychiatric disorder, or a medical condition or medication use that might interfere with physiological recording (e.g., severe asthma, cardiac conditions). Individuals were also excluded if they showed an abnormal cardiac rhythm during baseline recording in the laboratory. Individuals from the college community sample were excluded if they reported drinking less than four drinks (three drinks for women) at least twice per month in the past year, received a score greater than five on the Brief Michigan Alcohol Screening Test (Chan, Pristach, \& Welte, 1994), or reported weekly use of illicit or prescribed drugs, history of treatment for a substance use disorder, prenatal maternal substance abuse, or a neurological disorder, or if they were pregnant. Based on the Structured Clinical Interview for the DSM (First, Spitzer, Gibbon, \& Williams, 1997), all inpatient participants met dependence criteria for at least one substance. The percent of inpatients meeting substance use disorder criteria for various drugs was: alcohol $(80.8 \%)$, cocaine $(73.1 \%)$, opioids (65.4\%), marijuana (92.3\%), and other drugs (53.9\%). The absence of illicit drugs at the time of testing was confirmed by urinary analysis. Zero blood alcohol concentration in all participants was confirmed through breath analysis. 


\section{Self-report data}

Demographic data were collected from all participants. Multiple aspects of negative mood were measured using the Positive and Negative Affect Scale (PANAS, Watson, Clark, \& Tellegen, 1988), the Beck Depression Inventory II (BDI, Beck, Steer, Ball, \& Ranieri, 1996), and the Beck Anxiety Inventory (BAI, Beck \& Steer, 1993). The 20-item PANAS questionnaire asks participants how much they were experiencing a given affective state "right now." Responses to the 10 negative affect items $(1=$ "Very slightly or not at all" to 5 = "Extremely") were summed to create a current negative affect subscale. The sum scores from the 21-item ( $0=$ "Not At All" to $3=$ "Severely") BDI and BAI were used. The BDI and BAI assess symptoms of clinical depression and anxiety, reflecting the more stable affective state (i.e., mood) than the PANAS. Alcohol and other drug use behaviors were assessed with a modified version of the Rutgers Health and Human Development Project Alcohol and Drug Use Questionnaire (Robert J. Pandina, Labouvie, \& White, 1984). Individuals who reported daily cigarette smoking during the past year were defined as smokers. Alcohol use in the 30 days prior to the experiment (or, for inpatients, the 30 days prior to treatment entry) was measured using two variables: typical number of drinks consumed in a drinking occasion and typical number of drinking days per week. Alcohol-related problems were assessed using the Alcohol Dependence Scale (Skinner \& Horn, 1984). This is a 25-item scale inquiring about alcohol withdrawal symptoms, impaired control over drinking, awareness of a compulsion to drink, increased tolerance to alcohol, and salience of drinkseeking behavior over the past 12-month period.

Self-report ratings of arousal in response to each of the picture cues were also measured using a 9-point Likert-type scale of $1=$ calm or relaxed to $9=$ excited, jittery, or awake (Lang, Bradley, \& Cuthbert, 1999). The experimental design instructed participants to sit quietly for the duration of the baseline task and to respond verbally (with a number from 1 to 9) during the inter-stimulus interval to rate their arousal to, or the valence of, each picture cue. Average arousal scores for each of the four picture cue blocks were calculated and used in the analyses.

\section{Physiological assessment}

Respiratory data were continuously collected (1,000 samples per second) using a Powerlab data acquisition system (ADInstruments, Colorado Springs, CO) and analyzed with WinCPRS software (Absolute Aliens Oy, Turku, Finland). Off-line analysis of the signals was performed for each 5-min cue block separately. Respiratory volume and frequency were estimated from piezoelectric respiratory transducers fastened around the chest and abdomen, which are known to yield approximate estimates of respiratory volume (Huang, Young \& Tai, 2008). The thoracic band was fastened around the upper part of the chest, below the underarm, whereas the abdominal band was fastened approximately at the level of the navel. Both thoracic and abdominal bands were calibrated simultaneously using an $800 \mathrm{ml}$ bag into which participants were asked to breathe five times. Calibration coefficients were calculated (in units of $\mathrm{ml} / \mathrm{mV}$ ) separately for each band as $800 \mathrm{ml}$ divided by averaged respiration signals over the three breaths that were most closely equivalent to each other (measured in $\mathrm{mV}$ ) in response to calibration breathing. Tidal volume was calculated from thoracic and abdominal breath separately, by multiplying their recorded signals by the corresponding calibration coefficient. Absolute tidal volume was calculated as the average of thoracic and abdominal tidal volumes. The average thoracic tidal volume, average abdominal tidal volume and their ratio as thoracic-to-abdominal ratio as well as both the average respiratory frequency (i.e., respiration rate) and the standard deviation in frequency, over each 5-minute picture cue block (see below), were assessed. MVV was calculated from absolute tidal volume for each 5-minute picture cue block. 


\section{Procedures}

Each participant completed a laboratory session that began between 10 a.m. and 2 p.m. to minimize biological circadian variations in psychophysiology. After providing written informed consent, participants completed a series of questionnaires and were then moved to the physiological testing room. Participants were seated in a comfortable chair in front of a TV screen in a sound-attenuated, dimly lit room and physiological sensors were attached. A standardized low-demand baseline task (Jennings, Kamarck, Stewart, Eddy, \& Johnson, 1992) was completed to equate cognitive load across participants. Squares of various colors were flashed on a computer screen for periods of 5 seconds, followed by a 5 -sec blank screen. Participants were instructed to silently count the number of squares that were red. This procedure provides a more standardized baseline condition than simply relaxing, where some individuals might sleep, some might worry about the day's events, or engage in other idiosyncratic mental activity. Participants then viewed blocks of emotionally valenced pictures (Lang, Bradley, \& Cuthbert, 1999) and alcohol-related pictures (Stritzke, Breiner, Curtin, \& Lang, 2004; Tapert et al., 2003). Each picture cue block (negative emotional, positive emotional, neutral, and alcohol-related) included 15 pictures, which were presented twice. The presentation order of the picture cues within sets was randomized and the presentation order of the picture blocks was counterbalanced across participants. Cues were presented at a frequency of $0.1 \mathrm{~Hz}(5 \mathrm{~s}$ on/5 s off) with a $30 \mathrm{~s}$ inter-block interval. Selfreports of arousal in response to each picture cue were measured during the 5-s interstimulus (off) interval. All participants also performed a 5-minute paced breathing task in order to adjust for HRV in response to standard physiological process in studies described elsewhere (e.g., Udo et al., in press). During this task, participants were instructed to breathe at a rate of six breaths per minute by following an E-Z Air visual pacer (Biofeedback Foundation of Europe, Montreal, Canada). Although the majority of participants (73\%) performed this task after viewing picture cues, some (27\%) completed this task just prior to viewing the picture cues, after the baseline recording. To avoid a potential carryover effect of this breathing task, we controlled for whether participants received the paced breathing task prior to or following picture presentation.

\section{Analysis}

Data were analyzed using SAS Version 9.2. Self-report measures of negative affect/mood and alcohol use and problems were submitted to a principal components analysis to decrease the number of variables and to derive more global measures of these dimensions. As described below, two components were found for the self-report measures (termed Negative Mood and Alcohol Problems). Four respiratory variables were examined: average respiratory frequency $(\mathrm{Hz})$, the within-individual standard deviation in respiration frequency, the thoracic-to-abdominal respiratory volume ratio, and MVV ( $\mathrm{ml} / \mathrm{min})$. Natural $\log$ transformations were used for all respiratory variables in order to obtain normal distributions.

We performed a doubly multivariate ANOVA of the four respiratory measures as one multivariate series, with repeated respiratory response measures at baseline and during the four picture cue blocks (negative, positive, neutral, and alcohol) as the second repeated multivariate series, and examined main effects of the respiratory measures, the various picture types, and the two self-report factor scores, as well as all two-way and three-way interactions among these factors. This analysis assessed general psychophysiological characteristics across individuals with varying levels of negative mood and alcohol use under various experimental conditions. Also, in order to specifically analyze reactivity to the stimuli, we repeated these analyses only for the observations during the four picture blocks while covarying the baseline respiratory measures. All of these analyses controlled for gender, order of the paced breathing task (before vs. after picture presentation), and pack 
years of smoking. Significant effects from the doubly multivariate analysis were further probed for the purpose of illustration using correlations to examine the direction of relationship between continuous variables, and repeated measures of ANOVA to examine the nature of interaction effects. Additionally, to determine the effect of picture exposure, compared with baseline, we computed paired $t$-tests comparing baseline to the mean value of each respiratory measure across picture cue types.

\section{RESULTS \\ Description of Sample}

On average, participants reported relatively low levels of depression $(M=7.84, S D=7.76)$ and anxiety $(M=5.77, S D=5.91)$ symptoms as measured with the BDI and BAI, yet based on criteria set by Beck et al. (1996), 14\% had mild depression, 5\% had moderate depression, and 3\% had severe depression. Based on the suggested criteria for the BAI by Beck and Steer (1993), 18\% had mild anxiety, 7\% had moderate anxiety, and one individual met criteria for severe anxiety. Current negative affect was modest $(M=13.12, S D=3.44)$ compared to the maximum score of 50 on the PANAS.

Twenty-seven percent of the sample $(n=37)$ reported daily cigarette smoking during the past year. On average, participants reported drinking on 1.6 days $(S D=2.0)$ of the past 30 days, with a range of $0-14$ days. The average quantity of alcohol consumed per occasion over the past 30 days was $5.1(S D=3.8)$ standard drinks, ranging from 0 to 21 drinks, indicating that when participants drank, they tended to do so to excess. Eleven percent $(n=$ $15)$ of the sample reported no alcohol consumption in the past 30 days. Participants reported experiencing an average of $7.9(S D=5.6)$ alcohol-related problems based on their scores on the Alcohol Dependence Scale (Skinner \& Horn, 1984) which provides a quantitative measure of the severity of alcohol dependence symptoms over the past 12-month period, and only $2 \%(n=3)$ reported no negative consequences of use.

\section{Principal Component Analysis of Self-report Measures}

The six self-report variables (total BDI score, total BAI score, negative affect PANAS subscale score, typical quantity and frequency of alcohol consumption, and total Alcohol Dependence Scale score) were subjected to a principal components analysis (PCA). Two components with an eigenvalue $>1$ were retained. A two component solution accounted for $69 \%$ of the total variance. We rotated the components using a varimax rotation for interpretation. BDI, BAI, and negative affect PANAS scores loaded on the first component, which we labeled "Negative Mood" (Table 1). Higher scores indicated higher levels of negative mood. The quantity and frequency of drinking variables, and alcohol-related problems loaded on the second component labeled "Alcohol Problems." Higher scores indicated more alcohol drinking and problems. These two component (factor) scores were used for subsequent analysis. Note that the relatively low communality $\left(h^{2}\right)$ value of .55 for the PANAS score on the Negative Mood scale suggests that Negative Mood component score is driven less by the PANAS, state-specific mood scores than by the trait-like variables such as the BDI and BAI scores. Also note that the ADS score had a small but observable loading for the Negative Mood component, suggesting some connection between negative mood and alcohol problems.

\section{Respiration Analyses}

The doubly multivariate analysis analyzed baseline and response to picture cues as a repeated series, covarying for gender, order of paced breathing (before vs. after pictures) and pack years of smoking, yielded a significant between-subjects effect for the Negative Mood factor (across all respiratory variables and across all picture cue types), $F(1,127)=10.24, p$ 
$<0.01$. We also found a significant interaction between Negative Mood and type of respiratory measure, Wilks' Lambda $=0.91, F(4,124)=2.91, p<0.05$, suggesting that respiratory measures have different sensitivity to Negative Mood scores. Four repeated measures ANOVAs revealed that three respiratory measures - Thoracic to Abdominal Ratio, Respiratory Frequency, and Respiratory Variability -- were positively associated with Negative Mood scores $(F[1,133]=8.26,4.09,4.47$, respectively, all $p$ s $<0.05)$. When we further computed correlation coefficients between Negative Mood and each of the respiratory measures, we found consistently significant positive correlations with only one respiratory measure, Thoracic to Abdominal Ratio, ranging from $r=0.18$ to $r=0.27, p<$ 0.05 .

When we examined differences in respiratory responses to the various picture types for individuals with varying levels of Negative Mood and Alcohol Problems, while covarying baseline respiration measures, the effects reported above were not statistically significant. However, there was a significant between-subjects effect for the Alcohol Problems component, $F(1,123)=4.51, p<0.05$, suggesting that those with greater alcohol problems exhibited greater reactivity to all picture cues. Further, we found that two respiration measures at baseline, MVV and Thoracic to Abdominal Ratio, were strongly associated with overall respiratory responses to picture cues (across all picture cue types), $F(1,123)=23.34$, $p<.01$ and $F(1,123)=143.82, p<0.01$, respectively, suggesting that these two respiratory variables may be more sensitive to individual differences in reactivity than the other two respiration measures.

Additionally, to determine the effect of picture exposure, compared with baseline, we computed repeated measure t-tests comparing baseline to the mean value of each respiratory measure across picture cues.

\section{Changes from baseline}

We found large and significant changes between baseline values and picture cue responses on three of the four respiratory variables: an increase in thoracic/abdominal ratio $[t(134)=$ $2.01, p<.05]$, respiratory frequency $[t(134)=3.05, p<.005]$, and respiratory variability (standard deviation of respiratory frequency) $[t(134)=3.36, p=.001]$ (see Figure 1). The changes from baseline in these measures were unrelated to Negative Mood or Alcohol Problems.

\section{Self-reported Arousal, Negative Mood, and Alcohol Problems}

A repeated measures ANOVA on self-reported arousal found a significant stimulus type effect, Wilks' Lambda $=0.15, F(3,131)=255.02, p<0.01$. Participants reported being differentially aroused by the various cue types, in the order of negative emotional (unadjusted $M=6.1, S D=1.6$ ), positive emotional (unadjusted $M=4.8, S D=1.4$ ), alcoholrelated (unadjusted $M=3.9, S D=1.4$ ) and neutral (unadjusted $M=2.6, S D=1.0$ ) picture cues. The Negative Mood principal component was significantly related to self-reported arousal across stimuli, $F(1,133)=5.50, p<0.05$, with higher scores on Negative Mood associated with higher self-reported arousal generally across all cue types. The interaction between Negative Mood principal component score and cue type was not statistically significant for arousal ratings. There was no main effect for Alcohol Problems on arousal ratings. However, the interaction between Alcohol Problems and Picture Cue Type was statistically significant, Wilks' Lambda $=0.93, F(3,131)=3.31, p<.05$. Those with higher levels of Alcohol Problems self-reported greater arousal to alcohol-related picture cues, compared to their response to neutral picture cues, $F(1,133)=5.30, p<.05$. With just one exception, there were no significant correlations between arousal ratings and respiratory variables in response to any of the picture sets. 


\section{DISCUSSION}

The present results generally support a relationship between a chronic pattern of negative mood (primarily anxiety and depression in this study) and various indices of breathing, as described by Courtney (2009) for a clinical population. Ventilation tracks change in metabolic need (Hall, Field, Sahyun, Cutting, \& Tainter, 1933), or perhaps in anticipation of such changes as suggested by classical conditioning studies of respiratory responding (Gallego, Nsegbe, \& Durand, 2001; Van Diest et al., 2009). In this case, it appears that negative mood is associated with a generalized preparatory tendency to such mobilization. Such a pattern may, in future research, be found to render individuals with negative mood more vulnerable to hyperventilation when ventilation increases during conditions of stress and other sources of respiratory stimulation, such as altitude (Telch, Harrington, Smits, \& Powers, 2011), exercise (Roatta \& Farina, 2010), high ambient $\mathrm{CO}_{2}$ levels (Boyer \& Poppen, 1995; Broocks et al., 1997; Wallin, 2006), or more severe emotional stimulation. Evidence for a link with anxiety disorders, although cited (Gigliotti, 2010), is more controversial (Roth et al., 2002). Our findings indicate that greater respiratory activity may characterize chronic negative mood even in the absence of such disorder diagnoses. Lack of effect of picture cues on the relationship between respiration and negative mood suggests that the picture cues we used may not have evoked a sufficiently large emotional response to influence respiratory responses.

\section{Specific Relationship between Thoracic Breathing and Negative Mood}

The relationship between respiration and negative mood was strongest for thoracic to abdominal ratio, when examined across situations. This pattern has also been pointed out as characteristic of respiratory patterns among individuals with anxiety disorders (Schleifer, Ley, \& Spalding, 2002). It has also been found to be characteristic of individuals with symptoms of medically unexplained dyspnea (Courtney, van Dixhoorn, Greenwood, \& Anthonissen, 2011), which also is a common symptom of panic (Klein, 1993), where hyperventilation and dyspnea often co-occur (Freire, Perna, \& Nardi, 2010; Han et al., 2008).

Thoracic breathing may reflect the influence of muscle tension on respiration. Indeed, negative affect appears to be related to elevated levels of muscle tension (Jack, 2002), which, in turn, is related to sympathetic arousal (de Ruiter, Garssen, Rijken, \& Kraaimaat, 1989; Holt \& Andrews, 1989). Thoracic breathing tends to occur when abdominal muscle tension restricts movement of the diaphragm, requiring additional tension in the accessory respiratory muscles in the thorax (Hovanitz, Filippides, Lindsay, \& Scheff, 2002), which, in turn, through a positive feedback loop, may further increase sympathetic arousal through the muscle-sympathetic reflex loop, and thereby contribute to heightened negative affect. Such a pattern was suggested years ago by Garssen and Rijken (1986). Although evolutionary reasons for such a pattern during negative affect are speculative, it is possible that the pattern of abdominal muscle tension and thoracic breathing represents a protective mechanism during the fight-flight reflex, whereby abdominal muscle tension protects internal organs from injury. These organs are not protected by skeletal muscles, as are other vital organs in the trunk of the body. Our data suggest that patients with persistent negative affect (i.e., negative mood) have a continuing pattern of preparation for greater respiratory need, analogous to the fight-flight reaction. Once this preparatory respiratory pattern was taken into consideration in the model, respiratory reactivity was greater for those with high levels of alcohol problems, suggesting that there is another layer of vulnerability that goes beyond a general preparatory pattern for those with alcohol problems in adaptively responding to environmental perturbations. However, the affective valence of the picture cues had no effect on the relationship between respiratory responses and either the Alcohol 
Problems or Negative Mood factors. Perhaps other aspects of the task itself had sufficient affective load to produce the respiratory effects (e.g., carryover effects from affect-laden pictures, requirements to rate affective load, etc.).

Also, although resting respiration usually involves activity in the intercostal muscles (Campbell, Agostoni, \& Davis, 1970), physical exercise and increased metabolic need (as may occur during emotional reactions, where the body anticipates a need for muscular activity) tend to involve accessory muscles in the thorax and neck, to augment depth and force of breathing. Deeper breathing, which can occur during increased respiratory load, is accompanied by greater thoracic involvement. During quiet breathing, inspiratory activity is present parasternally and in the lower posterior area (Campbell et al., 1970, p 166), and there is evidence that this activity spreads from the upper spaces downwards with increasing size of the breath (thus ventilation). Conversely, expiratory activity is present even during quiet breathing in the lower four anterior ribs which spreads upwards with increasing size of breath. Although participants higher in negative mood did not breathe more deeply in this study, it is possible that negative mood may induce preparation for increased ventilation (as in expectation of motor activity, e.g., in the fight-flight reaction), hence the greater involvement of thoracic muscles in breathing.

Conversely, during sleep and most relaxed states, abdominal respiration predominates, where the muscles of the abdomen, pelvis, and lower back are relaxed, thus allowing ballistic actions of the diaphragm to allow the body to expand in those areas during inhalation. In response to emotional challenge, the muscles of the lower trunk tighten (Marras, Davis, Heaney, Maronitis, \& Allread, 2000; van der Velde \& Everaerd, 2001; Wolff et al., 2008), resulting in increased activity in the accessory muscles of the thorax to support breathing, as just described. This thoracic involvement may trigger, as well as respond to, sympathetic arousal through the muscle-sympathetic reflex system (Courtney, 2009; Courtney, van Dixhoorn, \& Cohen, 2008; van Dixhoorn, 2007) that may prepare the body for motor activity and greater metabolic need. Further research is needed to clarify whether a thoracic bias at rest in individuals with heightened, but sub-clinical levels of negative mood can be an early indicator of depression and/or anxiety symptom escalation. This consideration would support the common use of abdominal respiration training as a component in various behavioral treatment programs for problems involving anxiety (Han, Stegen, De Valck, Clement, \& Van de Woestijne, 1996; Hayama \& Inoue, 2012).

\section{Negative Affect and Alcohol Problems}

To the extent that some people drink to medicate themselves against negative affect (Cooper et al., 1995; Cox \& Klinger, 1988; Grant et al., 2009; Koob \& Le Moal, 2001; Labouvie \&

Bates, 2002; R. J. Pandina et al., 1992), respiratory therapies might be expected to indirectly ameliorate alcohol use and related problems by downregulating negative affect. Stress management methods, including relaxation interventions and various biofeedback approaches, have been found to be helpful in decreasing drinking among heavy drinkers (Andersson, Johnsson, Berglund, \& Ojehagen, 2009; Rohsenow, Smith, \& Johnson, 1985; Saxby \& Peniston, 1995; Shafil, Lavely, \& Jaffe, 1975; Steffen, 1975). No studies have yet examined respiratory-based relaxation or biofeedback strategies, although these have been used widely for general stress management (Chen et al., 2010; G. Paul, Elam, \& Verhulst, 2007; Yadav, Magan, Mehta, Sharma, \& Mahapatra, 2012).

\section{Arousal Ratings and Respiratory Activity}

Responsiveness of arousal ratings to the affective content of the various picture sets was more differentiated than respiratory responsiveness. Further, perception of emotional responsiveness and respiratory responsiveness are not closely linked. Indeed, even the 
association between negative mood and respiratory measures, although significant, was relatively small to moderate in range. It is not clear whether this reflects the size of the relationship between general emotional and respiratory activity, or whether it reflects a frequent desynchrony between verbal and psychophysiological indices of emotion that has been noted at least since the reviews of Rachman and Hodgson in the 1970's (Hodgson \& Rachman, 1974; Rachman \& Hodgson, 1974) and frequently replicated (Alpers \& Sell, 2008; Larry Michelson, Mavissakalian, \& Marchione, 1985; L. Michelson et al., 1990). This is for future research to decide.

\section{Limitations, Clinical Implications, and Future Directions}

Cross validation in other studies is necessary to confirm these findings, particularly in light of the large number of tests we conducted and the fact that the study design does not allow assessment of the causal direction between breathing patterns and either negative mood or drinking problems to be determined. Also, the current results used piezoelectric respiratory transducers, which capture speed of change, compared with inductive plethysmography, which captures volume of change. Thus, although the current measures of respiratory frequency should be accurate, our indirect measures of respiratory volume may contain measurement error. Additional research with direct assessment of thoracic muscle involvement (e.g., through surface EMG assessment of the chest and abdominal muscles) could help validate our findings. In general, respiratory response to picture cues was similar regardless of emotional content, which may have been due to the stimulation paradigm using still pictures (e.g., Kreibig, Wilhelm, Roth, \& Gross, 2007), the respiratory measures we assessed (e.g., Boiten, 1998), or the stronger effect of chronic negative mood over the emotional stimulation by picture cues. Further exploration is needed to explain how respiration interacts with other behavioral, physiological and neurological factors to affect emotional experience and substance use. Finally, it is possible that the range of affect induced by the picture cues in this study may have been too small to detect effects of either negative mood or alcohol problems. It is possible that use of stronger cues, e.g., an emotionally-involving motion picture, may have produced differential effects in response to emotional stimulation. Despite these limitations, these data are consistent with the use of respiratory interventions such as training in relaxed breathing for treating problems involving negative affect/mood and alcohol problems.

\section{Acknowledgments}

This study was supported in part by NIAAA grants R01 AA015248, R01 AA019511, K02 AA00325 and K01 AA017473, HHSN275201000003C, NIDA grants P20 DA017552, 3P20 DA017552-05S1, and K12DA031050, and NHLBI grant R01 HL089495.

\section{References}

Abelson JL, Weg JG, Nesse RM, Curtis GC. Persistent respiratory irregularity in patients with panic disorder. Biological Psychiatry. 2001; 49:588-595. [PubMed: 11297716]

Alpers GW, Sell R. And yet they correlate: Psychophysiological activation predicts self-report outcomes of exposure therapy in claustrophobia. Journal of Anxiety Disorders. 2008; 22:11011109. [PubMed: 18164177]

Alvarez SM, Katsamanis KM, Coyle SM, Lu SE, Macor M, Oikawa LO, Lowry SF, et al. Low-dose steroid alters in vivo endotoxin-induced systemic inflammation but does not influence autonomic dysfunction. Journal of Endotoxin Research. 2007; 13:358-368. [PubMed: 18182463]

Andersson C, Johnsson KO, Berglund M, Ojehagen A. Intervention for hazardous alcohol use and high level of stress in university freshmen: A comparison between an intervention and a control university. Brain Research. 2009; 1305(Suppl):S61-S71. [PubMed: 19699184] 
Bates ME, Buckman JF, Vaschillo EG, Fonoberov VA, Fonoberova M, Vaschillo B, Mezic I, et al. The redistribution of power: Neurocardiac signaling, alcohol and gender. PLoS One. 2011; 6:e28281. [PubMed: 22164260]

Beck, AT.; Steer, RA. Beck Anxiety Inventory Manual. San Antonio, TX: Harcourt Brace Jovanovich \& Company; 1993.

Beck AT, Steer RA, Ball R, Ranieri W. Comparison of Beck Depression Inventories -IA and -II in psychiatric outpatients. Journal of Personality Assessment. 1996; 67:588-597. [PubMed: 8991972]

Beckham AJ, Greene TB, Meltzer-Brody S. A pilot study of heart rate variability biofeedback therapy in the treatment of perinatal depression on a specialized perinatal psychiatry inpatient unit. Archives of Women's Mental Health. 2013; 16:59-65.

Blaber AP, Hartley T, Pretorius PJ. Effect of acute exposure to $3660 \mathrm{~m}$ altitude on orthostatic responses and tolerance. Journal of Applied Physiology. 2003; 95:591-601. [PubMed: 12716872]

Boiten FA. The effects of emotional behaviour on components of the respiratory cycle. Biological Psychology. 1998; 49:29-51. [PubMed: 9792483]

Boyer BA, Poppen R. Effects of abdominal and thoracic breathing upon multiple-site electromyography and peripheral skin temperature. Perceptual and Motor Skills. 1995; 81:3-14. [PubMed: 8532471]

Broocks A, Meyer TF, Bandelow B, George A, Bartmann U, Ruther E, Hillmer-Vogel U. Exercise avoidance and impaired endurance capacity in patients with panic disorder. Neuropsychobiology. 1997; 36:182-187. [PubMed: 9396017]

Brown TA, Chorpita BF, Barlow DH. Structural relationships among dimensions of the DSM-IV anxiety and mood disorders and dimensions of negative affect, positive affect, and autonomic arousal. Journal of Abnormal Psychology. 1998; 107:179-192. [PubMed: 9604548]

Buckman JF, White HR, Bates ME. Psychophysiological reactivity to emotional picture cues two years after college students were mandated for alcohol interventions. Addictive Behaviors. 2010; 35:786-790. [PubMed: 20409645]

Campbell, EJM.; Agostoni, E.; Newsom Davis, J. The respiratory muscles: mechanics and neural control. 2. Philadelphia, PA: Saunders; 1970.

Chan AWK, Pristach EA, Welte JW. Detection of Alcoholism in Three Populations by the Brief-Mast. Alcoholism: Clinical and Experimental Research. 1994; 18:695-701.

Chen KW, Comerford A, Shinnick P, Ziedonis DM. Introducing qigong meditation into residential addiction treatment: a pilot study where gender makes a difference. Journal of Alternative \& Complementary Medicine. 2010; 16:875-882.

Clark ME, Hirschman R. Effects of paced respiration on anxiety reduction in a clinical population. Biofeedback \& Self Regulation. 1990; 15:273-284. [PubMed: 2223892]

Cooper ML, Frone MR, Russell M, Mudar P. Drinking to regulate positive and negative emotions: A motivational model of alcohol use. Journal of Personality and Social Psychology. 1995; 69:990 1005. [PubMed: 7473043]

Courtney R. The functions of breathing and its dysfunctions and their relationship to breathing therapy. International Journal of Osteopathic Medicine. 2009; 12:78-85.

Courtney R, Cohen M. Investigating the claims of Konstantin Buteyko, M.D., Ph.D.: the relationship of breath holding time to end tidal $\mathrm{CO} 2$ and other proposed measures of dysfunctional breathing. Journal of Alternative and Complementary Medicine. 2008; 14:115-123.

Courtney R, van Dixhoorn J, Cohen M. Evaluation of Breathing Pattern: Comparison of a Manual Assessment of Respiratory Motion (MARM) and Respiratory Induction Plethysmography. Applied Psychophysiology and Biofeedback. 2008; 33:91-100. [PubMed: 18320303]

Courtney R, van Dixhoorn J, Greenwood KM, Anthonissen EL. Medically unexplained dyspnea: partly moderated by dysfunctional (thoracic dominant) breathing pattern. The Journal of Asthma. 2011; 48:259-265. [PubMed: 21341969]

Cox WM, Klinger E. A motivational model of alcohol use. Journal of Abnormal Psychology. 1988; 97:168-180. [PubMed: 3290306]

de Ruiter C, Garssen B, Rijken H, Kraaimaat F. The hyperventilation syndrome in panic disorder, agoraphobia and generalized anxiety disorder. Behaviour Research and Therapy. 1989; 27:447452. [PubMed: 2775154] 
Eddie D, Buckman JF, Mun EY, Vaschillo B, Vaschillo E, Udo T, Bates ME, et al. Different associations of alcohol cue reactivity with negative alcohol expectancies in mandated and inpatient samples of young adults. Addictive Behaviors. 2013; 38:2040-2043. [PubMed: 23396175]

First, MB.; Spitzer, RL.; Gibbon, M.; Williams, JBW. User's Guide for the Structured Clinical Interview for DSM-IV Axis I Disorders - Clinicial Version (SCID-CV). Washington, DC: American Psychiatric Press; 1997.

Franzblau SH, Echevarria S, Smith M, Van Cantfort TE. A preliminary investigation of the effects of giving testimony and learning yogic breathing techniques on battered women's feelings of depression. Journal of Interpersonal Violence. 2008; 23:1800-1808. [PubMed: 18319369]

Freire RC, Perna G, Nardi AE. Panic disorder respiratory subtype: psychopathology, laboratory challenge tests, and response to treatment. Harvard Review of Psychiatry. 2010; 18:220-229. [PubMed: 20597592]

Gallego J, Nsegbe E, Durand E. Learning in respiratory control. Behavior Modification. 2001; 25:495512. [PubMed: 11530713]

Garcia de Miguel B, Nutt DJ, Hood SD, Davies SJ. Elucidation of neurobiology of anxiety disorders in children through pharmacological challenge tests and cortisol measurements: a systematic review. Journal of Psychopharmacology. 2012; 26:431-442. [PubMed: 20643698]

Garssen B, Rijken H. Clinical aspects and treatment of the hyperventilation syndrome. Behavioural and Cognitive Psychotherapy. 1986; 14:46-68.

Gigliotti F. Mechanisms of dyspnea in healthy subjects. Multidisciplinary Respiratory Medicine. 2010; 5:195-201. [PubMed: 22958405]

Gold AR. Functional somatic syndromes, anxiety disorders and the upper airway: a matter of paradigms. Sleep Medicine Reviews. 2011; 15:389-401. [PubMed: 21295503]

Gomez P, Stahel WA, Danuser B. Respiratory responses during affective picture viewing. Biological Psychology. 2004; 67:359-373. [PubMed: 15294392]

Grant VV, Stewart SH, Mohr CD. Coping-anxiety and coping-depression motives predict different daily mood-drinking relationships. Psychology of Addictive Behavior. 2009; 23:226-237.

Hall VE, Field J, Sahyun M, Cutting WC, Tainter ML. Carbohydrate metabolism, respiration, and circulation in animals with basal metabolism heightened by dinitrophenol. American Journal of Physiology. 1933; 106:432-440.

Han JN, Stegen K, De Valck C, Clement J, Van de Woestijne KP. Influence of breathing therapy on complaints, anxiety and breathing pattern in patients with hyperventilation syndrome and anxiety disorders. Journal of Psychosomatic Research. 1996; 41:481-493. [PubMed: 9032712]

Han JN, Zhu YJ, Luo DM, Li SW, Van Diest I, Van den Bergh O, Van de Woestijne KP. Fearful imagery induces hyperventilation and dyspnea in medically unexplained dyspnea. Chinese Medical Journal. 2008; 121:56-62. [PubMed: 18208667]

Hayama Y, Inoue T. The effects of deep breathing on 'tension-anxiety' and fatigue in cancer patients undergoing adjuvant chemotherapy. Therapies in Clinical Practice. 2012; 18:94-98.

Henriques G, Keffer S, Abrahamson C, Horst SJ. Exploring the effectiveness of a computer-based heart rate variability biofeedback program in reducing anxiety in college students. Applied Psychophysiology \& Biofeedback. 2011; 36:101-112. [PubMed: 21533678]

Hodgson R, Rachman S. II. Desynchrony in measures of fear. Behaviour Research and Therapy. 1974; 12:319-326. [PubMed: 4155622]

Hoehn-Saric R, McLeod DR. Anxiety and arousal: physiological changes and their perception. Journal of Affective Disorders. 2000; 61:217-224. [PubMed: 11163423]

Holt PE, Andrews G. Hyperventilation and anxiety in panic disorder, social phobia, GAD and normal controls. Behaviour Research and Therapy. 1989; 27:453-460. [PubMed: 2775155]

Hovanitz CA, Filippides M, Lindsay D, Scheff J. Muscle tension and physiologic hyperarousal, performance, and state affectivity: assessing the independence of effects in frequent headache and depression. Applied Psychophysiology \& Biofeedback. 2002; 27:29-44. [PubMed: 12001884]

Huang YP, Young MS, Tai CC. Noninvasive respiratory monitoring system based on the piezoceramic transducer's pyroelectric effect. The Review of Scientific Instruments. 2008; 79:035103. [PubMed: 18377041] 
Jack MS. Respiratory instability: Relationship to diagnosis, anxiety sensitivity, and subjective anxiety in paced breathing and hyperventilation challenge. Dissertation Abstracts International: Section B: The Sciences and Engineering. 2002; 63(6-B):3009.

Jennings JR, Kamarck T, Stewart C, Eddy M, Johnson P. Alternate cardiovascular baseline assessment techniques: vanilla or resting baseline. Psychophysiology. 1992; 29:742-750. [PubMed: 1461961]

Karavidas MK, Lehrer PM, Vaschillo E, Vaschillo B, Marin H, Buyske S, Hassett A, et al. Preliminary results of an open label study of heart rate variability biofeedback for the treatment of major depression. Applied Psychophysiology \& Biofeedback. 2007; 32:19-30. [PubMed: 17333315]

Klein DF. False suffocation alarms, spontaneous panics, and related conditionsan integrative hypothesis. Archives of General Psychiatry. 1993; 50:31-42. [PubMed: 8422219]

Koob GF. Dynamics of neuronal circuits in addiction: reward, antireward, and emotional memory. Pharmacopsychiatry. 2009; 42(Suppl 1):S32-41. [PubMed: 19434554]

Koob GF, Le Moal M. Drug abuse: hedonic homeostatic dysregulation. Science. 1997; 278:52-58. [PubMed: 9311926]

Koob GF, Le Moal M. Drug addiction, dysregulation of reward, and allostasis. Neuropsychopharmacology. 2001; 24:97-129. [PubMed: 11120394]

Kreibig SD, Wilhelm FH, Roth WT, Gross JJ. Cardiovascular, electrodermal, and respiratory response patterns to fear- and sadness-inducing films. Psychophysiology. 2007; 44:787-806. [PubMed: 17598878]

Labouvie E, Bates ME. Reasons for alcohol use in young adulthood: validation of a three-dimensional measure. Journal of Studies on Alcohol. 2002; 63:145-155. [PubMed: 12033691]

Lang, PJ.; Bradley, MM.; Cuthbert, BN. International affective picture system (IAPS): Instruction manual and affective ratings: The Center for Research in Psychophysiology. University of Florida; 1999.

Marras WS, Davis KG, Heaney CA, Maronitis AB, Allread WG. The influence of psychosocial stress, gender, and personality on mechanical loading of the lumbar spine. Spine. 2000; 25:3045-3054. [PubMed: 11145816]

Michelson L, Mavissakalian M, Marchione K. Cognitive and behavioral treatments of agoraphobia: Clinical, behavioral, and psychophysiological outcomes. Journal of Consulting and Clinical Psychology. 1985; 53:913-925. [PubMed: 3910681]

Michelson L, Mavissakalian M, Marchione K, Ulrich RF, Marchione N, Testa S. Psychophysiological outcome of cognitive, behavioral and psychophysiologically-based treatments of agoraphobia. Behaviour Research and Therapy. 1990; 28:127-139. [PubMed: 2183758]

Pandina, RJ.; Johnson, V.; Labouvie, EW. Affectivity: A central mechanism in the development of drug dependence. In: Glantz, M.; Pickens, R., editors. Vulnerability to drug abuse. Washington, DC: American Psychological Association; 1992. p. 179-209.

Pandina RJ, Labouvie EW, White HR. Potential contributions of the life span developmental approach to the study of adolescent alcohol and drug use: The Rutgers Health and Human Development Project, a working model. Journal of Drug Issues. 1984; 14:253-268.

Panka GF, Oliveira MM, Franca DC, Parreira VF, Britto RR, Velloso M. Ventilatory and muscular assessment in healthy subjects during an activity of daily living with unsupported arm elevation. Revista Brasileira de Fisioterapia. 2010; 14:337-344. [PubMed: 20949234]

Paul M, Garg K. The effect of heart rate variability biofeedback on performance psychology of basketball players. Applied Psychophysiology \& Biofeedback. 2012; 37:131-144. [PubMed: 22402913]

Rachman S, Hodgson R. I. Synchrony and desynchrony in fear and avoidance. Behaviour Research and Therapy. 1974; 12:311-318. [PubMed: 4155621]

Ritz T, Wilhelm FH, Meuret AE, Gerlach AL, Roth WT. Do blood phobia patients hyperventilate during exposure by breathing faster, deeper, or both? Depression and Anxiety. 2009; 26:E60-E67. [PubMed: 19085969]

Roatta S, Farina D. Sympathetic actions on the skeletal muscle. Exercise and Sport Sciences Reviews. 2010; 38:31-35. [PubMed: 20016297] 
Roth WT, Gomolla A, Meuret AE, Alpers GW, Handke EM, Wilhelm FH. High altitudes, anxiety, and panic attacks: Is there a relationship? Depression and Anxiety. 2002; 16:51-58. [PubMed: 12219335]

Sato K, Kawamura T, Yamagiwa S. The "Senobi" breathing exercise ameliorates depression in obese women through up-regulation of sympathetic nerve activity and hormone secretion. Biomedical Research. 2011; 32:175-180. [PubMed: 21551954]

Schleifer LM, Ley R, Spalding TW. A hyperventilation theory of job stress and musculoskeletal disorders. American Journal of Industrial Medicine. 2002; 41:420-432. [PubMed: 12071494]

Shenefelt PD. Relaxation strategies for patients during dermatologic surgery. Journal of Drugs in Dermatology: JDD. 2010; 9:795-799. [PubMed: 20677535]

Siepmann M, Aykac V, Unterdorfer J, Petrowski K, Mueck-Weymann M. A pilot study on the effects of heart rate variability biofeedback in patients with depression and in healthy subjects. Applied Psychophysiology \& Biofeedback. 2008; 33:195-201. [PubMed: 18807175]

Skinner, HA.; Horn, JI. Alcohol Dependence Scale: User's Guide. Toronto, Canada: Addiction Research Foundation; 1984.

Stritzke WGK, Breiner MJ, Curtin JJ, Lang AR. Assessment of Substance Cue Reactivity: Advances in reliability, specificity, and validity. Psychology of Addictive Behaviors. 2004; 18:148-159. [PubMed: 15238057]

Tapert SF, Cheung EH, Brown GG, Frank LR, Paulus MP, Schweinsburg AD, Brown SA, et al. Neural response to alcohol stimuli in adolescents with alcohol use disorder. Archives of General Psychiatry. 2003; 60:727-735. [PubMed: 12860777]

Telch MJ, Harrington PJ, Smits JA, Powers MB. Unexpected arousal, anxiety sensitivity, and their interaction on $\mathrm{CO} 2$-induced panic: Further evidence for the context-sensitivity vulnerability model. Journal of Anxiety Disorders. 2011; 25:645-653. [PubMed: 21474277]

Thurber MR. Effects of heart-rate variability biofeedback training and emotional regulation on music performance anxiety in university students. Dissertation Abstracts International Section A: Humanities and Social Sciences. 2007; 68(3-A):889.

Tsang HW, Fung KM, Chan AS, Lee G, Chan F. Effect of a qigong exercise programme on elderly with depression. International Journal of Geriatric Psychiatry. 2006; 21:890-897. [PubMed: 16955451]

Tweeddale PM, Rowbottom I, McHardy GJ. Breathing retraining: effect on anxiety and depression scores in behavioural breathlessness. Journal of Psychosomatic Research. 1994; 38:11-21. [PubMed: 8126685]

Udo T, Mun EY, Buckman JF, Vaschillo EG, Vaschillo B, Bates ME. Reduced heart rate variability in heavy college drinkers: Potential side effects of unhealthy lifestyle choices. in press.

Van den Bergh O, Stegen K, Van Diest I, Raes C, Stulens P, Eelen P, Nemery B, et al. Acquisition and extinction of somatic symptoms in response to odours: a Pavlovian paradigm relevant to multiple chemical sensitivity. Occupational \& Environmental Medicine. 1999; 56:295-301. [PubMed: 10472302]

van der Velde J, Everaerd W. The relationship between involuntary pelvic floor muscle activity, muscle awareness and experienced threat in women with and without vaginismus. Behaviour Research and Therapy. 2001; 39:395-408. [PubMed: 11280339]

Van Diest I, Bradley MM, Guerra P, Van den Bergh O, Lang PJ. Fear-conditioned respiration and its association to cardiac reactivity. Biological Psychology. 2009; 80:212-217. [PubMed: 18955105]

Van Diest I, De Peuter S, Piedfort K, Bresseleers J, Devriese S, Van de Woestijne KP, Van den Bergh O. Acquired lightheadedness in response to odors after hyperventilation. Psychosomatic Medicine. 2006; 68:340-347. [PubMed: 16554402]

Van Dixhoorn, J. Whole-body breathing: A systems perspective on respiratory retraining. In: Lehrer, PM.; Woolfolk, RL.; Sime, WE., editors. Principles and practice of stress management. New York: Guilford Publications; 2007. p. 291-332.

Wallin BG. Regulation of sympathetic nerve traffic to skeletal muscle in resting humans. Clinical Autonomic Research. 2006; 16:262-269. [PubMed: 16810463] 
Watson D, Clark LA, Tellegen A. Development and validation of brief measures of positive and negative affect: The PANAS scales. Journal of Personality and Social Psychology. 1988; 54:10631070. [PubMed: 3397865]

Wells R, Outhred T, Heathers JA, Quintana DS, Kemp AH. Matter over mind: a randomisedcontrolled trial of single-session biofeedback training on performance anxiety and heart rate variability in musicians. PLoS ONE. 2012; 7:e46597. [PubMed: 23056361]

Wolff B, Burns J, Quartana P, Lofland K, Bruehl S, Chung O. Pain catastrophizing, physiological indexes, and chronic pain severity: tests of mediation and moderation models. Journal of Behavioral Medicine. 2008; 31:105-114. [PubMed: 18158618]

Yadav RK, Magan D, Mehta N, Sharma R, Mahapatra SC. Efficacy of a short-term yoga-based lifestyle intervention in reducing stress and inflammation: preliminary results. Journal of Alternative \& Complementary Medicine. 2012; 18:662-667. 

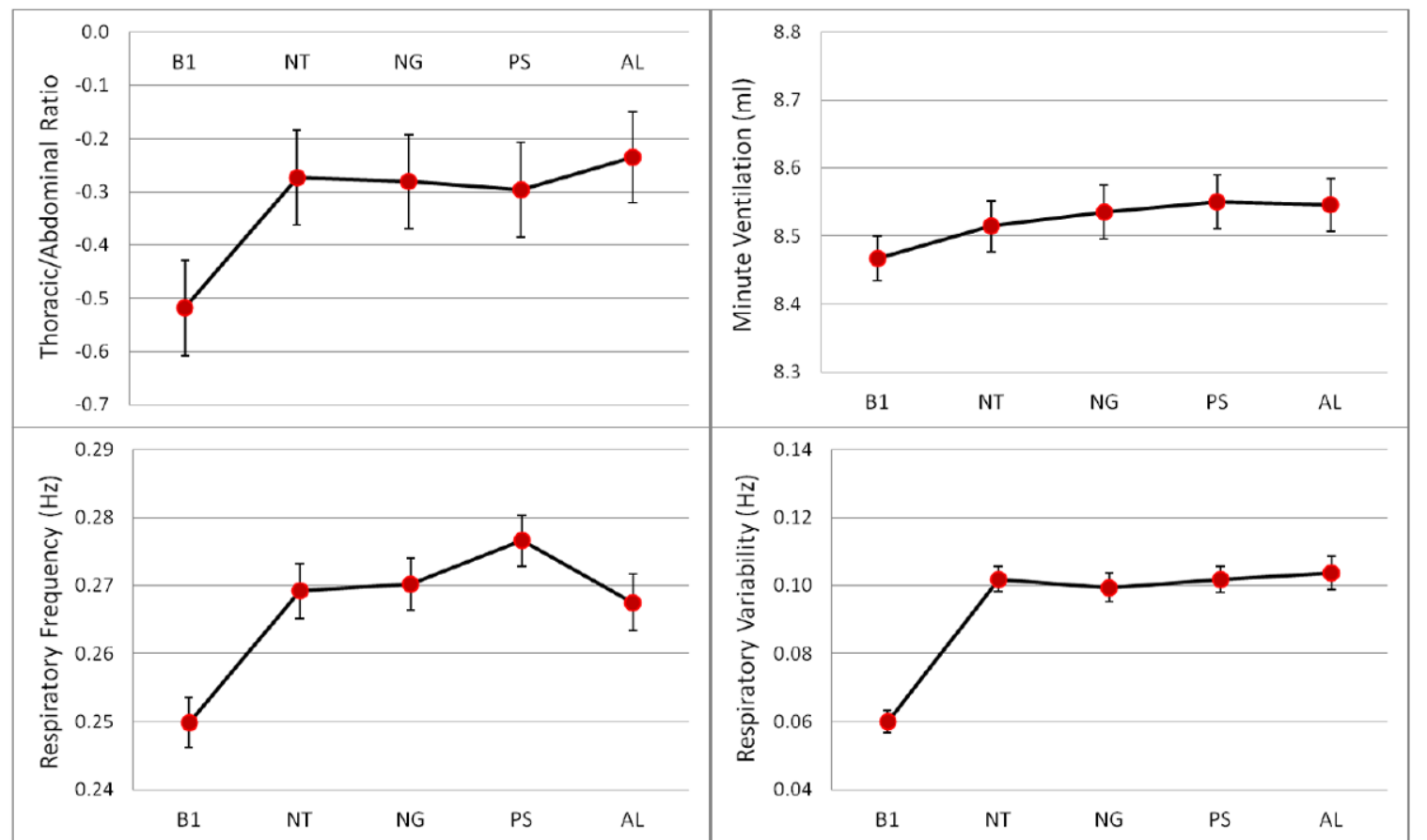

Figure 1.

Respiratory characteristics at baseline and in response to stimulus cue presentation. Note: Error bars are standard errors of estimate. All values are log transformed. "Respiratory variability" is the standard deviation of respiratory frequency. 


\section{Table 1}

Varimax Rotated Factor Pattern and Final Communality Estimates $\left(\mathrm{h}^{2}\right)$ of Psychosocial and Alcohol-Related Variables

\begin{tabular}{|c|c|c|c|c|}
\hline \multicolumn{2}{|c|}{ Components } & \multirow[t]{2}{*}{$h^{2}$} & \multirow[t]{2}{*}{ Item } & \multirow[t]{2}{*}{ Survey } \\
\hline 1 & 2 & & & \\
\hline .87 & .09 & .77 & Depressive symptoms & BDI \\
\hline .85 & .17 & .75 & Anxiety symptoms & BAI \\
\hline .73 & -.12 & .55 & Current negative affect & PANAS \\
\hline .00 & .80 & .64 & Drinks per drinking occasion in past 30 days & HHDP \\
\hline-.13 & .84 & .73 & Drinking days per week in past 30 days & HHDP \\
\hline .33 & .76 & .69 & Alcohol-related problems & ADS \\
\hline
\end{tabular}

Note $: N=136 . \mathrm{BDI}=$ Beck Depression Inventory II, BAI = Beck Anxiety Inventory, PANAS = Positive and Negative Affect Scale, HHDP = Rutgers Health and Human Development Project Alcohol and Drug Use Questionnaire, ADS = Alcohol Dependence Scale. 